\title{
Effectiveness of Diclofenac and Paracetamol Infusion for Post- operative Pain Relief in Total Abdominal Hysterectomy under Subarachnoid Block - A Comparative Study
}

\author{
Omprakash Sundrani ${ }^{1}$, Durga Shankar Patel ${ }^{2}$, Anand Masih Lakra ${ }^{3}$, Kishor Kumar Som $^{4}$, Kamal Kishore Sahare $^{5}$ \\ ${ }^{1}$ Associate Professor. Depaartment of Anaesthesiology \& Critical Care, Pt. J.N.M. Medical College . Raipur. C.G, ${ }^{2}$ Associate Professor. Depaartment of \\ Anaesthesiology, Government Medical College . Ambikapur, C.G. ${ }^{3}$ Professor \& HOD, Department of Anaesthesiology, Late Shri Lakhi Ram Agarwal \\ Memorial Medical College, Raigarh. C.G, ${ }^{4}$ Specialist Medical Officer, Dist. Hospital. Kanker. C.G, ${ }^{5}$ Professor \& HOD, Department of Anaesthesiology \& \\ Critical Care, Pt. J.N.M. Medical College . Raipur. C.G.
}

\section{Abstract}

Background: Aim: To compare the effectiveness of the diclofenac and paracetamol infusion for post operative pain relief in Hysterectomy patient under subarachnoid block in 24 hours. Subjects and Methods: This prospective randomized, clinical study was performed on 100 female patients belonging to American Society of Anesthesiologists grade I/II, aged 40-60 years of age undergoing hysterectomy under Subarachnoid block. These patients were divided in to two Groups A and B with 50 patients in each according to drug given for postoperative analgesia that is diclofenac $75 \mathrm{mg}$ and paracetamol $1000 \mathrm{mg}$ respectively. Pain was assessed by VAS at the completion of infusion for effective analgesia $(\mathrm{VAS}<3$ ). If patient did not achieve effective analgesia than rescue analgesia was provided with fentanly $20 \mathrm{mcg}$. Results: IV diclofenac $75 \mathrm{mg} 12$ hourly and paracetamol $1000 \mathrm{mg} 6$ hourly provides effective post operative pain relief. Paracetamol regimen shows better effect than diclofenac in 24 hours post operative period. Rescue analgesia with fentanyl $20 \mathrm{mcg}$ provides quick and effective pain relief in moderate to severe breakthrough pain in post hysterectomy patients. Conclusion: IV Paracetamol is superior in terms of effectiveness of pain relief and rescue analgesia required. Common side effect comprising of nausea, vomiting, pruritis were observed in few no of cases. No patients required special treatment. No serious side effect like hypotension, respiratory depression, bleeding, allergic reactions were observed.

Keywords: Paracetamol, Diclofenac, Hysterectomy, Postoperative pain relief.

Corresponding Author: Dr. Durga Shankar Patel, Associate Professor. Depaartment of Anaesthesiology, Government Medical College . Ambikapur, C.G.

Received: November 2019

Accepted: November 2019

\section{Introduction}

Post-operative pain is an unpleasant sensory, emotional and mental experience associated with autonomic, endocrinemetabolic, physiological and behavioral response. Consequences of inadequate pain control following surgery are significant and can result in immediate and long-term complications like hypoxemia, atelectasis, pneumonitis, deep venous thrombosis, pulmonary embolism, delayed recovery of bowel function, myocardial Ischemia and infarction, urinary retention, residual psychological trauma. ${ }^{[1]}$ It is well documented that pain reaches its maximum intensity in the early post operative period and continues for 24 hours after surgery. Post-operative pain in hysterectomy operation model is said to be representative of most postoperative situation. Clinical studies have found that $1000 \mathrm{mg}$ i.v paracetamol employed alone is just as effective as $30 \mathrm{mg}$ ketorolac, $75 \mathrm{mg}$ diclofenac or $10 \mathrm{mg}$ morphine. Ideal drug would be the one with quick onset $\&$ peak for sufficient duration of effective analgesia without side effects to manage post operative pain. Intravenous infusion being a part of daily nursing care has made its administration simple and solved the unpredictable bioavailability of other route like oral, rectal and intramuscular. In the present study objectives were to compare the effectiveness of diclofenac sodium and paracetamol infusion, number of rescue analgesia required, side effects and complications in 24hour of hysterectomy operation under sub arachnoids block.

\section{Subjects and Methods}

After obtaining Institutional Ethical Committee approval, written informed consent was obtained from 100 female patient of American Society of Anesthesiologists grade I/II, aged 40-60 years undergoing total abdominal hysterectomy.

Patients refusing for block, having bleeding disorders, getting upload analgesics, local infections at the site where needle for block is to be inserted, history of seizures, those with respiratory, cardiac, renal and hepatic disease and hypersensitivity to study drug were excluded from the study. Patient was kept nil orally 6 hours for solid, semisolid food 
\& milk. Patient was allowed to drink clear fluid $100-200 \mathrm{ml}$ 3 hours prior to anaesthesia. On arrival in operation theatre multipara monitor was attached and then baseline vital parameters including heart rate, noninvasive blood pressure, respitaory rate, oxygen saturation $(\mathrm{SpO} 2)$ and temperature were recorded. Intravenous access was established and ringer lactate $500 \mathrm{ml}$ was infused over a period of $15 \mathrm{~min}$. With the patient in lateral decubitus position and under all aseptic precautions lumbar puncture was done with a 25 G Quincke tip Lumbar Puncture needle at the level L3-4. Once free flow of Cerebrospinal fluid (CSF) was obtained Bupivacaine 0.5\% heavy $4 \mathrm{ml}$ and fentanyl citrate $20 \mathrm{mcg}$ injected. Patient was made supine and checked for sensory and motor blockade as well as vital parameter as mentioned above at $1 \mathrm{~min}, 5 \mathrm{~min}$, $10 \mathrm{~min}$, thereafter every $10 \mathrm{~min}$. Once satisfactory surgical anaesthesia level was attained, surgery was started. After the procedure was over patient were shifted to post anesthesia care unit and vitals parameter were checked. Randomization was achieved by computer generated random number table. Random group assigned was enclosed in a sealed opaque envelope to ensure concealment of allocation sequence. The patients and observer were blinded to the drug solution administered.

Assessment of pain was done by Visual analogue scale (VAS). It consists of an ungraduated straight $10 \mathrm{~mm}$ line marked at one end with the term no pain and at the other end the worst possible pain. The patient makes a cross on the line at the point that best approximates to their pain intensity as explained during pre anaesthetic visit on the day before surgery in his own language.

Patients were randomly allocated in to two groups of 50 each. Group A patients received diclofenac $75 \mathrm{mg}$ in $100 \mathrm{ml}$ normal saline (NS) at 0,12, 24 hours (12hourly) and plain NS $100 \mathrm{ml}$ at 6 and 18 hours, (two placebo infusion in order to preserve study blindness) while group B patients received Paracetamol $100 \mathrm{ml}(1000 \mathrm{mg})$ over a period of 15 minutes at 6 hourly interval $(0,6,12,18$ and 24 hours). Rescue analgesia was provided with fentanly $20 \mathrm{mcg}$ diluted in $2 \mathrm{ml} \mathrm{NS}$ and given IV slowly for break through pain. Pain was assessed for effective analgesia (VAS<3) at the completion of infusion and thereafter at every $5 \mathrm{~min}$ interval for $15 \mathrm{~min}$. If patient did not achieve effective analgesia than rescue analgesia was given. Side effects and complications were recorded and treated as per standard guidelines.

\section{Results \& Discussion}

Table 1: Patients characteristics and duration of anaesthesia (mean \pm SD)

\begin{tabular}{|l|l|l|l|}
\hline Parameters & $\begin{array}{l}\text { Group A } \\
(\mathbf{n = 5 0})\end{array}$ & $\begin{array}{l}\text { Group B } \\
(\mathbf{n = 5 0})\end{array}$ & P VALUE \\
\hline Age (years) & $47.52 \pm 7.06$ & $48.46 \pm 6.69$ & $>0.05$ \\
\hline Weight $(\mathrm{kg})$ & $53.94 \pm 3.68$ & $53.78 \pm 2.2$ & $>0.05$ \\
\hline $\begin{array}{l}\text { Duration of } \\
\text { anaesthesia }\end{array}$ & $85.3 \pm 10.8$ & $88.1 \pm 11.3$ & $>0.05$ \\
\hline
\end{tabular}

Uterine innervations stems from a variety of sources. Parasympathetic nerves stemming from S2 to S4 conglomerate into the cervical ganglion of frankenhauser. Sympathetic nerves, the predominant influence in uterine innervations, descend from T7-T8 to the internal iliac plexus bilaterally to meet their parasympathetic counterpart. Together these nerves innervate not only the uterus, but also the bladder and upper vagina. Within the uterus nerves terminate both within muscle fiber and the endometrial itself. The perineum is innervated by the pudendal nerve, which also enters the spinal cord at the S2-S4 level. Although these systems are primarily responsible for the function of the uterus. Perception of pain stems from different sites. Visceral afferent fiber from the uterine corpus transmit pain signals to the brain by entering the spinal cord at the T11-T12 levels. Whereas spinal cord levels S2-S4 receive signals from the cervix, vagina, and perineum. (Alhashemi J, et al 2006), ${ }^{[2]}$

Table 2: VAS scores at various time intervals (mean \pm SD)

\begin{tabular}{|l|l|l|l|}
\hline $\begin{array}{l}\text { Vas -Time } \\
\text { Interval } \\
\text { (Hour) }\end{array}$ & Group A & Group B & P Value \\
\hline 0 & $2.300 \pm 0.4600$ & $2.300 \pm 0.4600$ & $>0.05$ \\
\hline 1 & $2.300 \pm 0.4600$ & $2.200 \pm 0.4000$ & $>0.05$ \\
\hline 2 & $2.300 \pm 0.4600$ & $2.300 \pm 0.4600$ & $>0.05$ \\
\hline 3 & $4.700 \pm 0.8400$ & $4.280 \pm 0.4500$ & $<0.05$ \\
\hline 4 & $2.3200 \pm 0.4700$ & $2.260 \pm 0.4400$ & $>0.05$ \\
\hline 5 & $2.400 \pm 0.4900$ & $2.320 \pm 0.4700$ & $>0.05$ \\
\hline 6 & $5.880 \pm 0.6900$ & $4.240 \pm 0.4300$ & $<0.05$ \\
\hline 9 & $2.320 \pm 0.4700$ & $2.340 \pm 0.4800$ & $>0.05$ \\
\hline 12 & $5.300 \pm 0.4600$ & $3.960 \pm 0.3500$ & $<0.05$ \\
\hline 15 & $2.760 \pm 04300$ & $2.160 \pm 0.3700$ & $<0.05$ \\
\hline 18 & $4.070 \pm 0.7400$ & $2.280 \pm 0.4500$ & $<0.05$ \\
\hline 21 & $2.740 \pm 0.4400$ & $2.360 \pm 0.4800$ & $<0.05$ \\
\hline 24 & $3.260 \pm 2.3400$ & $2.680 \pm 0.4700$ & $>0.05$ \\
\hline
\end{tabular}

Table 3: Total Number of Rescue Analgesia Required

\begin{tabular}{|l|l|l|}
\hline Table 3: Total Number of Rescue Analgesia Required \\
\hline $3.02 \pm 0.38$ & Group B & P Value \\
\hline
\end{tabular}

Table 4: Incidence of Side Effects and Complications

\begin{tabular}{|l|l|l|}
\hline Parameters & Group A & Group B \\
\hline Nausea & $5(10 \%)$ & $4(08 \%)$ \\
\hline Vomiting & $4(08 \%)$ & $3(06 \%)$ \\
\hline Prurits & $1(02 \%)$ & $1(02 \%)$ \\
\hline Respiratory depression & 0 & 0 \\
\hline Hypotension & 0 & 0 \\
\hline
\end{tabular}

Paracetamol has a duration of analgesia shorter than diclofenac. The recommended dose regimen is $75 \mathrm{mg}$ every 12 hourly for diclofenac and $1 \mathrm{~g}$ every 6 hourly for paracetamol. The study was designed to take into account the different duration of analgesia and the recommended dosing interval of the two study drugs. Diclofenac sodium is available in $1 \mathrm{ml}$ ampoule containing $75 \mathrm{mg}$ while paracetamol is $1000 \mathrm{mg}$ in $100 \mathrm{ml}$ bottle ready to use. Diclofenac IV infusion was prepared by adding into $100 \mathrm{ml}$ of NS bottle. Infusion was given over a period of 15 minutes by nurse. ${ }^{[2]}$ placebo single dummy technique was used in group $\mathrm{D}$ to match paracetamol group and double blinding was maintained as patients and observer were unaware of the drugs used. Single observer assessed the pain and side effects were noted. Rescue analgesia was provided as and when required.

In our study the VAS at 0 hours (immediate post-operative) was $<3$ in both the groups. Less intensity of pain was due to residual effects of spinal anaesthesia. Fentanyl 20mcg was mixed in bupivacaine $0.5 \%$ heavy which not only improves the quality of spinal anaesthesia but also prolongs the 
duration of spinal anaesthesia. Therefore low pain score was observed. In 24 hours study period, group D at 12 and 24 hours showed VAS $>3$ and received intravenous infusion of diclofenac. It produces effective analgesia and not required rescue analgesia. At 6 and 18 hours group D patient showed VAS $>3$ and received $100 \mathrm{ml}$ of $\mathrm{NS}$ infusion. It was not effective and required rescue analgesia. When compared it with group $\mathrm{P}$ (patient received paracetamol $1000 \mathrm{mg}$ iv infusion at 0,6,12,18,24 hours). VAS was $>3$ at 6,12 and 18 hours and it produced effective analgesia at the end of infusion and did not require rescue analgesia. Paracetamol rapidly passes the blood brain barrier reaches a high concentration in the CSF and has an anti-nociceptive effect mediated by the central nervous system. This central effect has been regarded primarily as an indirect and reciprocal influence through cyclooxygenase enzyme inhibition, and probably through the serotoninergic system as well. Besides this central effect, it is accepted that paracetamol has a peripheral anti-inflammatory influence, though this effect is somewhat limited. Diclofenac sodium inhibits prostaglandin biosynthesis. Prostaglandin plays important role in causing pain and fever. (Bann warth B. et al 1992, ${ }^{[3]}$ Gupta A et al 2007) $)^{[4]}$

Yoganarasimha N. et al (2012), ${ }^{[5]}$ compared paracetamol infusion with diclofenac infusion for perioperative analgesia in 60 patients of age groups 18-60 years, ASA I\&II, undergoing lower abdominal surgeries under general anaesthesia. Study drug was given at the time of rectus abdominis closure. Post operatively pain intensity was recorded on VAS at various time interval for next 24 hours. Occurrence of any side effect was also noted. Whenever the VAS was $>7$, rescue analgesia was given. Patients in both the groups were comparable with respect to age, weight and duration of surgery. In diclofenac group pain intensity increases with time hours and reached peak level in 2 hour (VAS>7), rescue analgesia was given whereas in paracetamol group pain intensity also increased with hours but reached peak level at 6 hours after operations, hence rescue analgesia was given after 6 hours. This was statistically significant. Authors concluded that paracetamol infusion provides better and prolonged analgesia to the surgical patients post operatively as compared to diclofenac infusion.

In our study in group D breakthrough pain was observed in early post-operative period at 3 and 6 hours and at 18 hours in late post-operative period. Total 3 rescue analgesia were required during study period in group $\mathrm{D}$, while in group $\mathrm{P}$ only 1 rescue analgesia needed in early post-operative period at 3 hours, the difference being statistically significant. Yoganarasimha N. et al (2012), ${ }^{[5]}$ in their study showed that number of rescue analgesia required in the diclofenac group was significantly higher than paracetamol group.

Side-Effect: Nausea, vomiting and pruritis was observed in very few no of cases in both the groups in our study which was comparable. No major side effects like respiratory depression, bronchospasm, hypotension or allergic reaction was observed.

Hynes D. et al (2006), ${ }^{[6]}$ in their study reported only minor and common adverse effects, with no overall differences between the groups.

Mehta A. et al (2007), ${ }^{[7]}$ observed that incidence of side effects like nausea, vomiting was low and was comparable in both the groups.

\section{Conclusion}

In our pain model (hysterectomy operation under SAB) diclofenac $75 \mathrm{mg}$ i.v infusion 12 hourly and paracetamol $1000 \mathrm{mg}$ i.v infusion 6 hourly provided effective postoperative pain relief. Paracetamol i.v infusion regimen (1000mg 6 hourly) shows better effect than diclofenac regimen ( $75 \mathrm{mg} 12$ hourly) in 24 hours post-operative period. Rescue analgesia with fentanyl $20 \mathrm{mcg}$ provides quick and effective pain relief in moderate to severe breakthrough pain in hysterectomy patients.

\section{References}

1. Rao M, Acute post operative pain. Ind J Anaesth. 2006; 50(5): 340-344.

2. Alhashemi J, Alotaibi Q, Mashat M, Nasr T, Kaki A, Analgesic effects of intravenous paracetamol vs. ibuprofen after ceasarean section. European journal of Anaesthesiology June 2006 ; 23: 183-85

3. Bannwarth B, Netter P, Lapicque F, Gillet P, Pere P, Boccard E, et al. Plasma and cerebrospinal fluid concentrations of paracetamol after a single intravenous dose of propacetamol. British Journal of Clinical Pharmacology 1992; 34: 79-81

4. Gupta A : Evidence based medicine in day surgery current opinion in Anaesthesiology 2007; 20: 520-5.

5. Yoganarasimha N, Raghvendra TR, Radha MK, Amitha S, and Sridhar $\mathrm{K}$. Comparision of paracetamol infusion with diclofenac infusion for perioperative analgesia. RRJMHS 2012; 1 (1):18-22.

6. Hynes D McCarroll M, Hiesse PO. Analgesic efficacy of parentral paracetamol (propacetamol) and diclofenac in post- operative orthopedic pain Acta Anaesthesiology scand 2006;50:374-381

7. Mehta A, Bakshi R, Bhasin S. Efficacy of Diclofenac sodium for post op pain relief in patients undergoing Laparoscopic sterilization. The internet Journal of Anaesthesiology . 2007;16(1)

Copyright: () the author(s), publisher. Academia Anesthesiologica International is an Official Publication of "Society for Health Care \& Research Development". It is an open-access article distributed under the terms of the Creative Commons Attribution Non-Commercial License, which permits unrestricted non-commercial use, distribution, and reproduction in any medium, provided the original work is properly cited.

How to cite this article: Sundrani O, Patel DS, Lakra AM, Som KK, Sahare KK. Effectiveness of Diclofenac and Paracetamol Infusion for Post-operative Pain Relief in Total Abdominal Hysterectomy under Subarachnoid Block - A Comparative Study. Acad. Anesthesiol. Int. 2019;4(2):268-70.

DOI: dx.doi.org/10.21276/aan.2019.4.2.60

Source of Support: Nil, Conflict of Interest: None declared. 